\title{
Survey on Microgrid: Power Quality Improvement Techniques
}

\author{
Chitra Natesan,, ${ }^{1,2}$ Senthil Kumar Ajithan, ${ }^{3}$ \\ Priyadharshini Palani, ${ }^{2}$ and Prabaakaran Kandhasamy ${ }^{2}$ \\ ${ }^{1}$ Anna University, Chennai 600025, India \\ ${ }^{2}$ Department of Electrical \& Electronics Engineering, SKP Engineering College, Tiruvannamalai 606611, India \\ ${ }^{3}$ Department of Electrical \& Electronics Engineering, Velammal Engineering College, Chennai 600066, India
}

Correspondence should be addressed to Chitra Natesan; psk_siva@hotmail.com

Received 22 November 2013; Accepted 6 February 2014; Published 16 March 2014

Academic Editors: P. D. Lund and B. Mwinyiwiwa

Copyright (C) 2014 Chitra Natesan et al. This is an open access article distributed under the Creative Commons Attribution License, which permits unrestricted use, distribution, and reproduction in any medium, provided the original work is properly cited.

\begin{abstract}
Microgrid became one of the key spot in research on distributed energy systems. Since the definition of the microgrid is paradigm of the first time, investigation in this area is growing continuously and there are numerous research projects in this moment all over the world. The increased infiltration of nonlinear loads and power electronic interfaced distribution generation system creates power quality issues in the distributed power system. In this paper, a comprehensive survey on microgrid to improve the power quality parameters is taken as the main objective. Furthermore, the detailed investigations are explored in this paper for the enhancement of power quality issues with the help of an optimization technique, filters, controllers, FACTS devices, compensators, and battery storage.
\end{abstract}

\section{Introduction}

Microgrid [1] may be defined as an agglomeration of distributed generation (DG) units usually linked through power electronic based devices (voltage source inverter) to the utility grid. DG units can be built with nonconventional energy sources such as fuel cells, wind turbines, hydroelectric power, and solar energy. Microgrid can function either tied to the grid or isolated from the grid. The impact of power quality hitches is concerning while linking microgrid to the main grid and it could become a foremost area to investigate. If unbalance in voltage is alarming, the solid state circuit breaker (CB), connected between the microgrid and utility grid, will open to isolate the microgrid. When voltage unbalance is not so intense, $\mathrm{CB}$ remains closed, resulting in sustained unbalance voltage at the point of common coupling (PCC). Generally power quality problems are not new in power system, but rectification methodology has increased in recent years.

Maintaining a near sinusoidal power distribution bus voltage at rated magnitude and frequency is referred to as electric power quality. In addition, the energy supplied to a customer must be interrupted from the reliability perception. Voltage unbalance, harmonic content, increased reactive power demand, and frequency deviation are the foremost power quality hitches which affect the utility grid.

Generally, current harmonic and voltage-frequency imbalance increase losses in AC power lines. A synchronous reference frame based current control loop and conventional PI regulator are used for voltage-frequency regulation $[2,3]$. Voltage unbalance has been mitigated by indirect current control technique in [4]. DGs are capable of offering high flexibility to robustness along with versatile control of active and reactive power (PQ) in both grid tied and islanded mode, which has been investigated in [5]. In order to improve the DG controller performance, several modification methodologies have been carried out in $[6,7]$. The main power quality parameters include voltage and frequency along with harmonic distortion, which has been improved by adopting Static VAR Compensator (SVC) and Shunt Active Power Filter (SAPF) in [8]. The voltage and frequency control mode are adopted in microgrid under grid tied or islanded in order to regulate voltage and frequency in microgrid $[9,10]$. Droop control technique provides 
the efficient methodology to enhance the power quality parameter like active and reactive power control both in grid and autonomous operation. Droop control technique has been employed in $V$ and $I$ to provide PQ control in microgrid, which has been investigated in [11].

This paper has been organized into seven sections. Section 2 discusses the Particle Swarm Optimization (PSO) applicability in the enhancement of power quality. Section 3 provides the regulation of power quality using compensators. The control of APC for the improvement of power quality is deliberated in Section 4. Role of battery storage in improving power quality is highlighted in Section 5. Section 5 confers the part of controllers in power quality enhancement. Section 6 provides the FACTS device's role in improving power quality. Section 7 discusses the use of filters in power quality enhancement. Finally, conclusion is stated in Section 8 .

\section{Applicability of PSO Technique to Mitigate Power Quality Problems}

In this section, the authors Al-Saedi et al. [2, 3, 12] emulate an outline of PSO technique applicability to power quality enhancement in an autonomous microgrid in order to address the power quality parameters like voltage regulation, frequency regulation, power sharing, steady state response, dynamic response, and THD analysis.

In order to meet the power quality requirement, PSO algorithm based control strategy for real time self-tuning of control parameters has been used in this approach. This control strategy is composed of two control loops. The first one is a synchronous reference frame based current control loop which acts as an inner loop and the other one is a power control loop based on the conventional PI regulators which acts as an outer loop. The effectiveness of proposed approach is evaluated with Matlab/Simulink under different operating conditions, that is, during island mode and load changes.

Reference [2] seems to be the first research article that discusses the usage of PSO in the area of power quality enhancement in microgrid. In this paper, power controller utilizes active power-reactive (PQ) power control strategy and voltage-frequency (Vf) control strategies are adopted in autonomous microgrid. In order to maintain the microgrid voltage and frequency within regulating limits, Vf control strategy is implemented during autonomous mode. The PQ control strategy is adopted during load changes.

In the approach presented by [3], the effectiveness of PSO in sharing the required load power between the utility and the microgrid was successfully analyzed. In their problem formulation, the investigation of the proposed power control stratagem is analyzed with two modes of operation. In mode 1 , it is assumed that the load demand is more than the generated power of the microgrid. Therefore, the difference in power is compensated by the utility. In case the power generation is greater than the load demand, the control strategy will switchover the operation to mode 2 and so the additional power is instinctively supplied to the main grid.
Al-Saedi et al. extended their research [12] by employing the same optimization process as in [2] in order to evaluate the steadystate response, dynamic response, and also the harmonic distortion in addition to regulating voltage and frequency. In their work, the proposed power control stratagem is that the distributed generation unit follows Vf control mode when the microgrid undergoes load change or islanded, so that system voltage and frequency are regulated. Furthermore, the controller is also investigated to confirm the good response during steady state and dynamic state. The effectiveness of PSO to enhance the harmonic distortion was also successfully validated with the proposed control strategy.

A different formulation for voltage harmonic elimination is addressed in [13]; Ray et al. compared their approach with individual PSO and SPWM technique. In order to reduce voltage harmonics, Ray introduced a method which is a combination of PSO based PWM inverter along with a sine PWM inverter. As a first step, they eliminated 5th, 7th, 11th, and 13th output voltage and selected lower order harmonics by applying Selective Harmonic Elimination (SHE) technique based on PSO algorithm. After eliminating lower order harmonics, the presence of harmonics with higher order is suppressed by PWM inverter by varying the carrier wave phase angle which generates dominant harmonics. The results are evaluated with Matlab/Simulink as well as DSP TMS320F2407A of Texas Instruments.

\section{Compensators in Microgrid for Power Quality Enhancement}

In $[14,15]$, the authors highlighted the use of compensators in reduction of current harmonics in a distributed microgrid.

In the area of harmonic current sharing, Wang et al. [14] employed a load compensator. Analyzing the problems of the grid-side inductances, the load compensator is designed with two impedance loops: virtual fundamental impedance (VFI) loop and variable harmonic impedance (VHI) loop. In this compensator the active power-frequency $(P-\omega)$ droop controller and reactive power-voltage $(Q-V)$ droop controllers performances are supported by VFI loop. The negativesequence circulating current is also alleviated with introducing VFI [16]. A section of grid-side inductance near the frequencies of dominant harmonics is counterbalanced by the VHI loop and also attains a proper harmonic current sharing with all the DG inverters. The positive harmonic resistances attain filtering of harmonic current and the curbing of resonance.

Castilla et al. excellently analyzed the shortcomings of standard resonant current control and successfully adapted a novel resonant control scheme [15]. The novel control employs a proportional resonant compensator (PRES) and a resonant harmonic (RESH) compensator. PRES tracks the current reference signal's fundamental component, whereas the current harmonics with most significance were attenuated by RESH compensator. In order to break the mechanism for disturbance injection, Castilla et al. adopted the conventional current control that is interlinked in a different pattern. The main contribution of this work was to introduce a control 
scheme that includes low computational load and low harmonic distortion of current. In reality, the computational load of the novel control is accurately identical to the conventional resonant control, whereas during abnormal grid situations it decreases the current harmonic distortion considerably.

\section{Role of APC in Power Quality Improvement}

A different problem interpretation was projected by Vechiu et al. [17] and Balanuta et al. [18] where they regarded the enhancement of harmonic current and power factor as the focus parameters [17]. In microgrid, the AC bus is interfaced with renewable energy sources by an active power conditioner (APC). Hence, for the power quality enhancement, this APC has to be controlled.

In [17], a novel control strategy with PI controllers and hysteresis control is projected. The projected control strategy uses a compensation technique that forces the current from the microgrid to become balanced and sinusoidal by making the APC to compensate the nonlinear load current. The novel control strategy helps in allowing the energy to be injected into the microgrid, compensating the current harmonics, correcting the power factor, and balancing the PCC supply voltage. The shortcoming of using the hysteresis control is varying switching frequency which will generate a band of significant side harmonics in the region of the switching frequency. The rationality of the control strategy is checked using Matlab simulation software. Vechiu et al. have done the case study and the following are the inferences.

(1) Compensation of harmonics: the projected control strategy reduced the THD of microgrid current to $3 \%$ and it also allowed the microgrid current to be sinusoidal.

(2) Correction of power factor: the power factor among the current from microgrid and the voltage from supply is made to unity with the help of the APC control strategy.

(3) Unbalanced load: a three-phase load of resistive type induces unbalance in the system, which is compensated by using the APC.

With the APC control, the degree of unbalance is less than $0.8 \%$ which is below the permitted level of $2 \%$ by international standards.

Balanuta et al. [18] compared the performance of two active power conditioners linked to a microgrid with four wires. The first model of APC was formed on a voltage structure with two levels and the other model of APC was formed on an NPC voltage structure (Neutral Point Clamped) with three levels. An indirect control scheme is used for both models in order to improve the various power quality issues like voltage unbalance, harmonic level, and power factor. The main focus of their work is curtailing the disturbance generated by the different loads.

The following conclusions are made at the end of the investigation of the systems implemented in Matlab software.

(1) Microgrid without APC: a large disturbance is present on the voltage waveform, which is produced by the
TABLE 1

\begin{tabular}{lccc}
\hline Phase & THD vg [\%] & THD ig [\%] & $\begin{array}{c}\text { Unbalance vg } \\
{[\%]}\end{array}$ \\
\hline a & 23.99 & 96.79 & \\
b & 16.98 & 110.48 & 4.96 \\
c & 18.73 & 105.66 & \\
\hline
\end{tabular}

TABLE 2

\begin{tabular}{lccc}
\hline Phase & $\begin{array}{c}\text { THD } \\
\text { vg [\%] }\end{array}$ & $\begin{array}{c}\text { THD } \\
\text { ig [\%] }\end{array}$ & $\begin{array}{c}\text { Unbalance vg } \\
{[\%]}\end{array}$ \\
\hline $\mathrm{a}$ & 6.64 & 11.80 & \\
$\mathrm{~b}$ & 7.56 & 8.98 & 2.3 \\
$\mathrm{c}$ & 7.42 & 7.92 & \\
\hline
\end{tabular}

TABLE 3

\begin{tabular}{lccc}
\hline Phase & $\begin{array}{c}\text { THD } \\
\text { vg [\%] }\end{array}$ & $\begin{array}{c}\text { THD } \\
\text { ig [\%] }\end{array}$ & $\begin{array}{c}\text { Unbalance vg } \\
{[\%]}\end{array}$ \\
\hline A & 1.97 & 4.74 & \\
B & 2.25 & 3.33 & 1.5 \\
C & 2.16 & 2.16 & \\
\hline
\end{tabular}

nonlinearity of the loads. The indicators of power quality values without APC are given in Table 1.

(2) Microgrid with two-level APC: the level of voltage THD is reduced below the permitted limit. The problem of unbalance in voltage remains unsolved and is greater than the tolerable limit. The values of power quality parameters with two-level APC are given in Table 2.

(3) Microgrid with three-level APC: the voltage is balanced and sinusoidal. The voltage and the microgrid current are inphase with each other. The voltage and current harmonics are reduced and less compared to the two-level APC. The values of power quality parameters with three-level APC are given in Table 3.

In Kamel and Kermanshahi [19], the performance of storage batteries in upgrading the dynamic performance consequent to islanding process was explored.

Kamel and Kermanshahi are credited by introducing storage batteries to enhance the dynamic behavior of the microgrid during and consequence of islanding occurrence. Kamel and Kermanshahi extended their work to study the undesirable frequency drop by emphasizing the load shedding strategy. The authors illustrated the role of storage batteries in microgrid performance with two cases: the microgrid's dynamic performance during and consequent of islanding with no storage batteries is examined in the first case, whereas in the second case the transient and dynamic responses of the MG with two storage batteries are described. The process of islanding in microgrid results in voltage drop and frequency deviation which were reduced in the presence of storage batteries. 


\section{Power Quality Improvement with Controllers}

In this section, Savaghebi et al. [20, 21], Prodanovic and Timothy [22], and Hornik and Zhong [23] discussed the control scheme for compensating the voltage unbalance in microgrid.

The method presented in $[20,21]$ worked for voltage unbalance compensation at the point of DG terminal.

The problems in the papers $[20,21]$ are defined as voltage unbalance compensation at PCC and voltage quality enhancement at Sensitive Load Bus (SLB). In their problem formulation, the use of the hierarchical control scheme which comprises primary and secondary control levels is proposed.

In [20], the primary level with local controllers of DG employs a PI controller to generate the unbalance compensation reference for the microgrid DGs. The low bandwidth communication links are used to transmit the reference generated by the PI controller to the primary level local controllers of DG. Identical power rating distributed generator units are used in this work, which take care of compensation due to unbalance.

In the scheme of [20] the following drawbacks are identified.

(1) The author analyzed the voltage unbalance compensation for an autonomous mode microgrid at point of common coupling.

(2) The author originated the unbalance by using linear unbalanced load.

(3) The author tackled the problem using droop controllers for the load current compensation in the positive sequence component.

Analyzing the shortcomings of the approach in [20], Savaghebi et al. extended his work by considering harmonic distortion during unbalanced condition due to the use of nonlinear loads [21]. The primary control level along with a selective virtual impedance loop supports the controlling of each DG unit with different rated powers, so that the compensation effort sharing is achieved. By adopting the secondary control loop the compensation of negative sequence components of SLB fundamental voltage is achieved. In addition the positive sequence and negative sequence of main harmonics of SLB voltage are also compensated. Since the primary level gets an appropriate control signal from the ancillary level of control, the harmonic and voltage unbalance of SLB is compensated. As listed in the shortcomings of [20], the author evaluated the microgrid analysis for both grid connected and islanded modes.

A different problem interpretation was projected in [22], where they regarded improvement of voltage and power sharing. A control method was proposed, in which the control tasks were separated in the frequency domain. In order to allocate the control among a central controller and local controllers for every inverter, the principle is adopted. Voltage and power sharing are regulated centrally and a low-bandwidth communication link was used to distribute the orders. Functions of waveform quality are regulated in high bandwidth regulators distributed to every local inverter. During transients and steady state, the circulating currents are evaded.

In the area of enhancing the power quality issues in the microgrid, Hornik and Zhong [23] adapted a twofold control method in three-phase four-wire microgrids. In their work, they focussed on the improvement of voltage THD and current THD. The control strategy for an inverter in the microgrid is comprised of a current controller and voltage controller which is implemented for each phase. $H_{\infty}$ repetitive approach is used in both controllers. The $H_{\infty}$ repetitive based voltage controller plays a major role in the synchronization of the microgrid and also generating and dispatching power in the microgrid under nonlinear and unbalanced load. Similarly the $H_{\infty}$ repetitive based current controller helps in exchanging pure current in the grid.

\section{Facts Devices in Power Quality Improvement}

In this section, the authors Lee et al. [24, 25] deliberated about voltage quality enrichment using FACTS devices.

A new method for the mitigation of voltage variations by using the D-STATCOM was deliberated by Lee et al. $[24,25]$. The D-STATCOM works as distinct conductances of positive sequence and negative sequence at the fundamental frequency. The voltage of positive sequence is renovated to its nominal value and also the voltage of negative sequence is suppressed to an acceptable value by using the D-STATCOM. With respect to the fluctuation of voltage at the location of installation, the commands of conductance are tuned actively to reduce the voltage variation resulting from the variable source of renewable energy and load change. In the low voltage microgrids, the voltage distortion will be high which results in harmonic currents. To suppress the harmonic current and to track the fundamental current, a regulation of resonant current is employed [26] in this work. Regarding the DSTATCOM location the following two inferences are identified.

(1) Regulating performance is worse when the DSTATCOM is near to the source.

(2) Regulating performance is best when the DSTATCOM is at the end of transmission line.

In [25], the authors Lee et al. extended their work by projecting a D-STATCOM that recognizes positive sequence admittance and negative-sequence conductance to regulate positive-sequence voltage and to overcome negativesequence voltage. With respect to deviation in positivesequence voltage and percentage of imbalanced voltage, both positive-sequence shunt admittance and negative-sequence series conductance were actively regulated. In case of DGs variation or load variation, voltage quality can be sustained at an acceptable level. In order to control the D-STATCOM's fundamental current and also to suppress harmonic current, a selective harmonic compensation based proportionalresonant $(\mathrm{PR})$ current regulator $[27,28]$ is implemented. 
With the implementation of DSP platform, the D-STATCOM control is recognized.

In addition to the mitigation voltage variations, Lee et al. also extended their work by evaluating the performances of the voltage regulation through the installation of DSTAT$\mathrm{COM}$ at different buses. At the end of the analysis the following conclusions are obtained.

(1) Voltage regulation performance seems to be best when DSTATCOM is placed at the end of the line.

(2) Less improvement occurs in voltage fluctuations if DSTATCOM is close to the voltage source.

(3) In comparison to the right side of the installation point, the left side gives better performance.

Lee et al. expanded the simulation results by coordinating the DSTATCOM with other devices such as SVC and OLTC.

(1) Since the reactive power compensation can be regulated in a stepwise manner, the DSTATCOM changes the same in a continuous manner; the integration of DSTATCOM with SVC helps in reducing the DSTATCOM's power rating.

(2) Though OLTC manages the fluctuations in voltage due to DG's power variation, the DSTATCOM injects required reactive power with quick response time compared to OLTC. Therefore, the integration of DSTATCOM with OLTC is preferable.

(3) Similar to the operation of DSTATCOM with other devices, multiple DSTATCOMs are implemented together to restore the voltage.

\section{Contribution of Filters in Power Quality Improvement}

In an attempt to reduce harmonics or THD in microgrids, various filters are used. This section includes those filters, which are presented by Illindala and Venkataramanan [29], Yao and Xiao [30], Wang and Li [31], Sheng-Qing et al. [32], and Mehta and Singh [33].

Observing the fact that the issue of THD had become a major problem for microgrid inverters, Illindala et al. used frequency/sequence selective filters in their work. If the gap among desired and undesired frequencies is narrow, then the frequency/sequence selective filters can be used in threephase three-wire power systems. Such frequency/sequence selective filters can be integrated in the voltage source inverters (VSI) that include bandpass and bandstop segments which are combined into a single transfer function of complex-coefficient aimed at the three-phase space vectors. The negative sequence components are efficiently filtered by the sequence selective filter and the harmonic selective filters are utilized to eliminate the fundamental frequency and to pass the 5th and 7th harmonics.

In [30], the authors used a single phase grid-tied inverter control with nonlinear loads to enhance the grid current and output voltage waveform quality. They adopted a hysteresis current control. In conventional control, the current from a nonlinear load pollutes the grid. It prompted the authors to project a control to overcome this problem. In gridtied mode, to eradicate the nonlinear load impact on the grid current, the load current feedback is included into the inductor current control loop. However, in standalone mode, waveform quality of output voltage was improved by including the compensation of load current into the filter inductor current loop. The selection of filter inductor is done. The method of control is easy and simple to be attained.

A three-phase cascaded delayed signal cancellation phase-locked loop (CDSC-PLL) was projected by Wang and Li [31]. The whole idea was to rapidly detect the particular harmonics and to reduce those harmonics. The projected method uses CDSC operation of $\alpha \beta$-frame to extricate the particular harmonics. The unwanted harmonics were absolutely eradicated, which leads to zero detection error of steady state. To track several harmonics concurrently, several CDSC operators can be arrayed in parallel. The unnecessary utilization of CDSC subsystems in parallel can be avoided by employing an equal CDSC subsystem number to the harmonic number to be detected, when the input has several harmonics. For a small frequency variation, the entire system was unresponsive and to control significant frequency shift, a frequency feedback loop (FFL) is used. Very short transient and small memory operating expense are the added benefits of the system. The results are evaluated experimentally in the platform of dSPACE DS1103 under different states. The following inferences are attained at the end of the examination.

(1) With a stable frequency at grid $(50 \mathrm{~Hz})$, the CDSCPLL detects the distinctive harmonics.

(2) With a marginally varied frequency at grid (50$49.9 \mathrm{~Hz}$ ), the CDSC-PLL detects the distinctive harmonics. When the frequency variation is triggered, simultaneously it introduces the harmonics.

(3) With a substantially altered frequency at grid (50$45 \mathrm{~Hz}$ ), the CDSC-FFL-PLL detects the distinctive harmonics and simultaneously imposes the harmonic shift and the alteration of frequency.

(4) A diode rectifier generates distinctive harmonics that are detected by using the CDSC-PLL.

Calculating the problem of harmonics in Microgrid, Sheng-Qing et al. [32] realized the opportunity to propose a novel predicting method of harmonic current. The whole idea was to reduce harmonic current. In this paper work, Empirical Mode Decomposition (EMD) and Intrinsic Mode Regression (SVR) (EMD-SVR) theory based forecast method for harmonic current is proposed and it is effectively utilized in the microgrid Hybrid Active Power Filter (HAPF) harmonic current prediction. Simulation results were carried out in Matlab/Simulink. First using the EMD method, the harmonic current was split into every harmonic current, afterwards by using the distinct kernel function in the SVR module to forecast distinct times harmonic currents at the subsequent time; conclusively, the anticipated value of every harmonic weighted calculation, harmonic currents at the subsequent time were precisely forecasted, and harmonic current least 
error compensation was attained. When manipulating the prediction method based on EMD and SVR hybrid intelligent forecast model, the HAPF filter effects can be significantly upgraded which is investigated experimentally.

Pointing out the problem of power quality in using renewable energy sources, Mehta and Singh [33] introduced a control method with active power filter (APF). They primarily focused on harmonics reduction as well as voltage unbalance enhancement. A single stage three-phase DG system based on RES was employed to reduce the cost and to increase the efficiency; it also incorporates the APF functionality. The generated real power from RES is injected to the grid by the inverter interfaced with grid. The inverter works like shunt APF and/or injects power to the grid. Hence, the necessity for a supplementary power conditioning equipment was eradicated. This leads to enhance the power quality at PCC. The current at the grid is balanced and sinusoidal with power factor at unity, by compensating the unbalanced nonlinear load effects connected near PCC like unbalance current, harmonic current, and reactive power of load. Simulation results are carried out under two modes of operation. At the end of the examination the following inferences are obtained.

Mode 1. Injecting power from RES and improving power quality.

(1) Varying nonlinear load-with the control method, the results approve excellent dynamic performance.

(2) Nonlinear load with unbalanced condition-at PCC, even in presence of unbalanced load, the currents from supply are balanced.

Mode 2. Enhancing power quality with no generation of power.

In this mode, the inverter interfaced with grid acts as shunt APF (SAPF).

(1) Varying nonlinear load-with SAPF, the results approve excellent dynamic performance. There is a smooth variation in the current at grid, when a change occurs in the current at load.

(2) Nonlinear load with unbalanced condition-with the projected control, the currents at the supply are balanced after compensation.

\section{Conclusion}

In this paper, an attempt has been taken for the comprehensive survey on microgrids in both grid tied and islanded mode in order to improve the power quality parameters. All approaches expressed in this survey concentrate on the different power quality issues due to the increased usage of nonlinear loads and power electronic interfaced distributed generation system. Hence, different power quality enhancement methodologies like optimization technique, filters, controllers, FACTS devices, compensators, and battery storage were successfully discussed in this work.

\section{Conflict of Interests}

The authors declare that there is no conflict of interests regarding the publication of this paper.

\section{References}

[1] R. H. Lasseter, "Microgrids," in Proceedings of the IEEE Power Engineering Society Winter Meeting, vol. 1, pp. 305-308, New York, NY, USA, January 2002.

[2] W. Al-Saedi, S. W. Lachowicz, D. Habibi, and O. Bass, "Power quality enhancement in autonomous microgrid operation using Particle Swarm Optimization," International Journal of Electrical Power \& Energy Systems, vol. 42, no. 1, pp. 139-149, 2012.

[3] W. Al-Saedi, S. W. Lachowicz, D. Habibi, and O. Bass, "Power flow control in grid-connected microgrid operation using Particle Swarm Optimization under variable load conditions," International Journal of Electrical Power \& Energy Systems, vol. 49, pp. 76-85, 2013.

[4] H. Kim, T. Yu, and S. Choi, "Indirect current control algorithm for utility interactive inverters in distributed generation systems," IEEE Transactions on Power Electronics, vol. 23, no. 3, pp. 1342-1347, 2008.

[5] A. Kahrobaeian and Y. A.-R. I. Mohamed, "Interactive distributed generation interface for flexible micro-grid operation in smart distribution systems," IEEE Transactions on Sustainable Energy, vol. 3, no. 2, pp. 295-305, 2012.

[6] A. Timbus, M. Liserre, R. Teodorescu, P. Rodriguez, and F. Blaabjerg, "Evaluation of current controllers for distributed power generation systems," IEEE Transactions on Power Electronics, vol. 24, no. 3, pp. 654-664, 2009.

[7] D. Pr and V. Ramanarayanan, "Decentralized parallel operation of inverters sharing unbalanced and nonlinear loads," IEEE Transactions on Power Electronics, vol. 25, no. 1, pp. 3015-3022, 2010.

[8] G. Xiaozhi, L. Linchuan, and C. Wengan, "Power quality improvement for microgrid in islanded mode," Procedia Engineering, vol. 23, pp. 174-179, 2011.

[9] C. Wang, Z. Xiao, and S. Wang, "Synthetical control and analysis of microgrid," Industrial Automation of Electric Power Systems, vol. 32, no. 7, pp. 98-103, 2008.

[10] F. Blaabjerg, R. Teodorescu, M. Liserre, and A. V. Timbus, "Overview of control and grid synchronization for distributed power generation systems," IEEE Transactions on Industrial Electronics, vol. 53, no. 5, pp. 1398-1409, 2006.

[11] I.-Y. Cheng, W. Liu, D. A. Cartes, E. G. Collins Jr., and S.I. Moon, "Control methods of inverter-interfaced distributed generators in a microgrid system," IEEE Transactions on Industry Applications, vol. 46, no. 3, pp. 1078-1088, 2010.

[12] W. Al-Saedi, S. W. Lachowicz, D. Habibi, and O. Bass, "Voltage and frequency regulation based DG unit in an autonomous microgrid operation using Particle Swarm Optimization," International Journal of Electrical Power \& Energy Systems, vol. 53, pp. 742-751, 2013.

[13] R. N. Ray, D. Chatterjee, and S. K. Goswami, "Reduction of voltage harmonics using optimisation-based combined approach," IET Power Electronics, vol. 3, no. 3, pp. 334-344, 2010.

[14] X. Wang, F. Blaabjerg, and Z. Chen, "Autonomous control of inverter-interfaced Distributed Generation units for harmonic current filtering and resonance damping in an islanded microgrid," in Proceedings of the IEEE Energy Conversion Congress and 
Exposition (ECCE '12), pp. 211-218, IEEE, Raleigh, NC, USA, September 2012.

[15] M. Castilla, J. Miret, A. Camacho, J. Matas, and L. de Vicuna, "Reduction of current harmonic distortion in three-phase gridconnected photovoltaic inverters via resonant current control," IEEE Transactions on Industrial Electronics, vol. 60, no. 4, pp. 1464-1472, 2011.

[16] X. Wang, F. Blaabjerg, and Z. Chen, "An improved virtual impedance for droop-controlled parallel three-phase voltage source inverters," in Proceedings of the IEEE Energy Conversion Congress and Exposition (ECCE '12), pp. 2466-2473, Raleigh, NC, USA, September 2012.

[17] I. Vechiu, G. Gurguiatu, and E. Rosu, "Advanced active power conditioner to improve power quality in microgrids," in Proceedings of the 9th International Power and Energy Conference (IPEC '10), pp. 728-733, Singapore, October 2010.

[18] C. Balanuta, I. Vechiu, and G. Gurguiatu, "Improving microgrid power quality using three-phase four-wire active power conditioners," in Proceedings of the 16th International Conference on System Theory, Control and Computing (ICSTCC '12), pp. 1-5, Sinaia, Romania, October 2012.

[19] R. M. Kamel and B. Kermanshahi, "Enhancement of micro-grid dynamic performance subsequent to islanding process using storage batteries," Iranian Journal of Science and Technology, Transaction B: Engineering, vol. 34, no. B6, pp. 605-618, 2010.

[20] M. Savaghebi, A. Jalilian, J. C. Vasquez, and J. M. Guerrero, "Secondary control scheme for voltage unbalance compensation in an islanded droop-controlled microgrid," IEEE Transactions on Smart Grid, vol. 3, no. 2, pp. 797-807, 2012.

[21] M. Savaghebi, A. Jalilian, J. C. Vasquez, and J. M. Guerrero, "Secondary control for voltage quality enhancement in microgrids," IEEE Transactions on Smart Grid, vol. 3, no. 4, pp. 1893-1902, 2012.

[22] M. Prodanovic and C. Timothy, "High-quality power generation through distributed control of a power park microgrid," IEEE Transactions on Industrial Electronics, vol. 53, no. 5, pp. 1471-1482, 2006.

[23] T. Hornik and Q.-C. Zhong, " $\mathrm{H}^{\infty}$ repetitive current-voltage control of inverters in microgrids," in Proceedings of the 36th Annual Conference of the IEEE Industrial Electronics Society (IECON '10), pp. 3000-3005, Glendale, Ariz, USA, November 2010.

[24] T.-L. Lee, S.-H. Hu, and Y.-H. Chan, "Design of D-STATCOM for voltage regulation in microgrids," in Proceedings of the 2nd IEEE Energy Conversion Congress and Exposition (ECCE '10), pp. 3456-3463, Atlanta, Ga, USA, September 2010.

[25] T. Lee, S. Hu, and Y. Chan, "D-STATCOM with positivesequence admittance and negative-sequence conductance to mitigate voltage fluctuations in high-level penetration of distributed generation systems," IEEE Transactions on Industrial Electronics, vol. 60, no. 4, pp. 1417-1428, 2013.

[26] M. Castilla, J. Miret, J. Matas, L. G. de Vicuna, and J. M. Guerrero, "Linear current control scheme with series resonant harmonic compensator for single-phase grid-connected photovoltaic inverters," IEEE Transactions on Industrial Electronics, vol. 55, no. 7, pp. 2724-2733, 2008.

[27] D. N. Zmood and D. G. Holmes, "Stationary frame current regulation of PWM inverters with zero steady-state error," IEEE Transactions on Power Electronics, vol. 18, no. 3, pp. 814-822, 2003.

[28] F. Blaabjerg, R. Teodorescu, M. Liserre, and A. V. Timbus, "Overview of control and grid synchronization for distributed power generation systems," IEEE Transactions on Industrial Electronics, vol. 53, no. 5, pp. 1398-1409, 2006.

[29] M. Illindala and G. Venkataramanan, "Frequency/sequence selective filters for power quality improvement in a microgrid," IEEE Transactions on Smart Grid, vol. 3, no. 4, pp. 2039-2047, 2012.

[30] Z. Yao and L. Xiao, "Control of single-phase grid-connected inverters with nonlinear loads," IEEE Transactions on Industrial Electronics, vol. 60, no. 4, pp. 1384-1389, 2011.

[31] Y.-F. Wang and Y. Li, "Three-phase cascaded delayed signal cancellation PLL for fast selective harmonic detection," IEEE Transactions on Industrial Electronics, vol. 60, no. 4, pp. 1452 1463, 2013.

[32] L. I. Sheng-Qing, Z. E. N. G. Huan-Yue, L. I. N. Hong-Zhi, L. I. Wei-Zhou, and X. U. Wen-Xiang, "A new harmonic current forecasting method for HAPF of microgrid," TELKOMNIKA Indonesian Journal of Electrical Engineering, vol. 11, no. 4, pp. 2002-2007, 2013.

[33] G. Mehta and S. P. Singh, "Power quality improvement through grid integration of renewable energy sources," IETE Journal of Research, vol. 59, no. 3, pp. 210-218, 2013. 


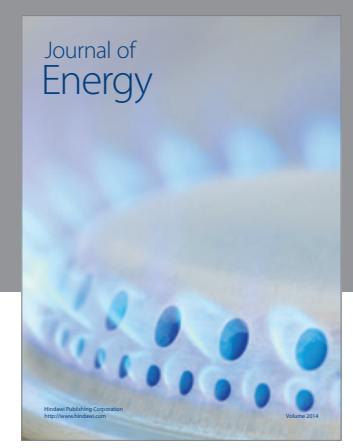

Journal of

Industrial Engineering
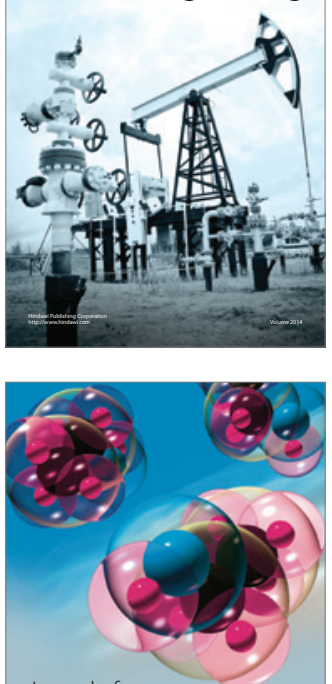

Fuels
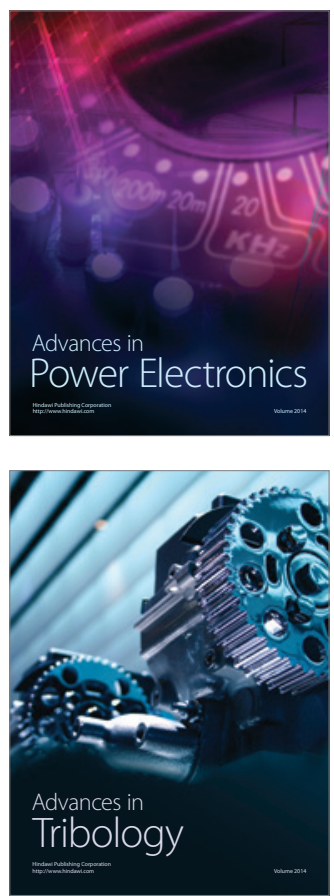

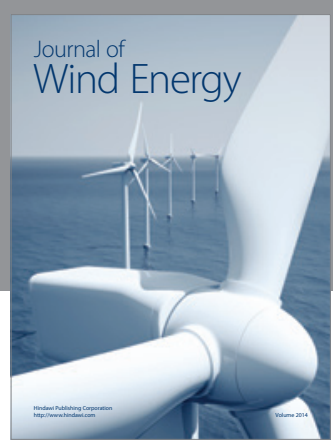

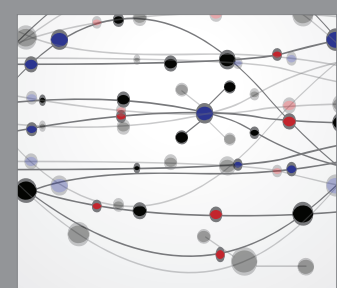

The Scientific World Journal

Submit your manuscripts at http://www.hindawi.com

Journal of

Structures
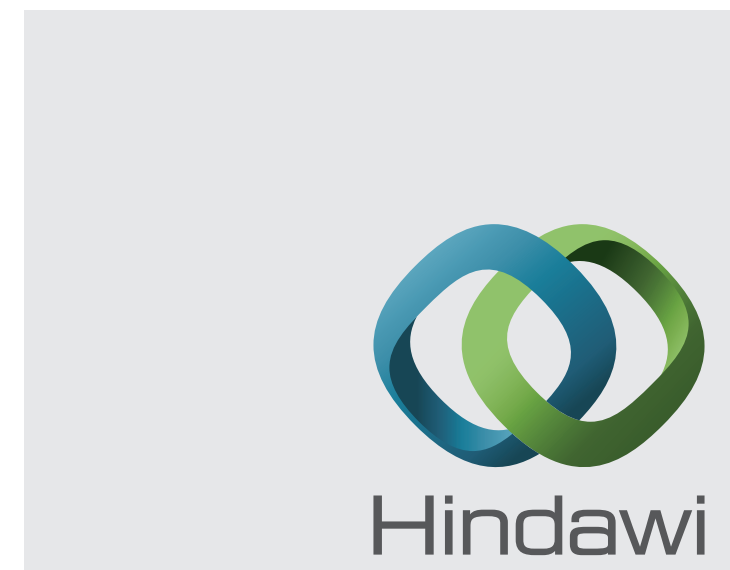

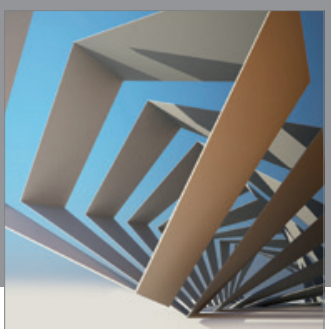

Rotating

Machinery
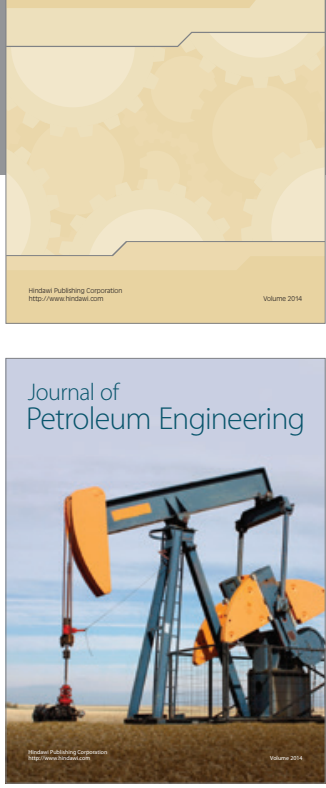

Journal of

Solar Energy
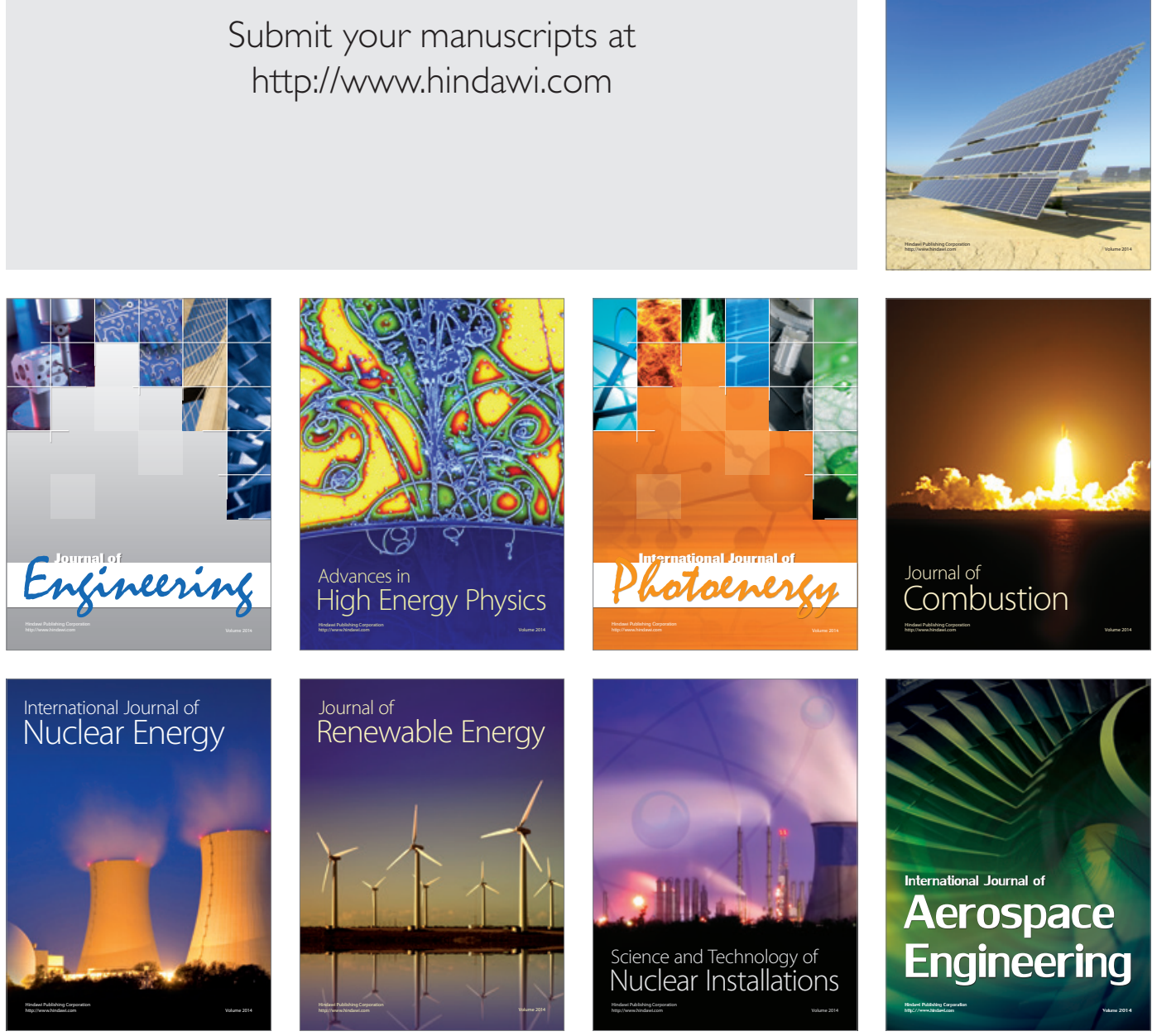